\title{
Effect of a New Sapogenol Derivative (AG-07) on Cell Death via Necrosis ${ }^{+}$
}

\author{
Yalcin Erzurumlu 1, Ozgur Tag 2, Sinem Y1lmaz 1,4, Petek Ballar 1,* and Erdal Bedir ${ }^{3, *}$ \\ 1 Faculty of Pharmacy, Department of Biochemistry, Ege University, Izmir 35040, Turkey \\ 2 Bionorm Natural Products Production \& Marketing Co., Izmir 35477, Turkey \\ 3 Faculty of Engineering, Department of Bioengineering, Izmir Institute of Technology, Izmir 35430, Turkey \\ 4 Faculty of Engineering, Department of Bioengineering, Lanya Alaaddin Keykubat University, Alanya, \\ Antalya 07450, Turkey \\ * Correspondence: ballar.petek@gmail.com (P.B.); erdalbedir@gmail.com (E.B.); \\ Tel.: +90-532-504-5157 (P.B.); +90-537-624-1281 (E.B.) \\ + Presented at the 2nd International Conference on Natural Products for Cancer Prevention and Therapy, \\ Kayseri, Turkey, 8-11 November 2017.
}

Published: 14 November 2017

\begin{abstract}
Saponins, plant secondary metabolites with high molecular weight, carry sugar groups on the triterpenic or steroidal skeleton. They exhibit biological activities such as anti-HIV, immunoadjuvant, analgesic and anticancer. Saponins have been reported to induce apoptosis, autophagy, stress responses and also inhibit cell cycle and invasion-migration in cancer cells. As saponins have partially weaker anti-cancer properties, they are often used as starting compounds for semi-synthesis of biologically more active molecules. With the same aim, we have focused on cycloartane-type saponins from Astragalus species to prepare potent compounds with cytotoxic activity. Cycloastragenol, a major sapogenol encountered only in Astragalus genus, was used to synthesize astragenol (AG) and then AG-07, a novel compound. Herein, we report the anticancer activities of AG and AG-07 against HCC1937 and HeLa cells by WST-1 assay. Additionally, levels of proteins associated with cell death are examined by immunoblotting. Cell death was also evaluated using flow cytometry and $\mathrm{AO} / \mathrm{EB}$ staining. In comparison to $\mathrm{AG}$, our results show that AG-07 is more cytotoxic. Furthermore, it induces formation of necrosis-associated protein fragments and necrosis-mediated cell death. In conclusion, AG-07, has a lethal effect on cancer cells through non-apoptotic cell death mechanism.
\end{abstract}

Keywords: triterpenoid sapogenin; astragenol; cycloastragenol; necrosis; HCC1937; HeLa

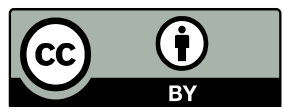

(C) 2017 by the authors. Licensee MDPI, Basel, Switzerland. This article is an open access article distributed under the terms and conditions of the Creative Commons Attribution (CC BY) license (http://creativecommons.org/licenses/by/4.0/). 